Acta Theriologica 38 (1): 81 - 91, 1993.

PL ISSN $0001-7051$

\title{
Choice of resting sites by female foxes Vulpes vulpes in a mountainous habitat
}

\author{
Jean-Steve MEIA and Jean-Marc WEBER
}

\begin{abstract}
Meia J.-S. and Weber J.-M. 1993. Choice of resting sites by female foxes Vulpes vulpes in a mountainous habitat. Acta theriol. 38: $81-91$.

The resting sites of seven radio-tracked Red fox Vulpes vulpes (Linnaeus, 1758) vixens were determined in the Swiss Jura mountains. During their nocturnal active period, foxes rested above ground near their foraging areas. In daytime, some foxes always used dens in areas with little cover, while some other individuals often rested above ground when cover was abundant. Weather did not influence the choice of the resting place, except in extreme conditions. Each fox used several resting places, sometimes moving from one to another during the day, especially when lying above ground.

Institut de Zoologie, Université de Neuchâtel, Chantemerle 22, CH-2007 Neuchâtel, Switzerland

Key words: Vulpes vulpes, females, resting site, den
\end{abstract}

\section{Introduction}

As in most habitats, foxes are mainly nocturnal in the Swiss Jura mountains (J.-M. Weber et al., in prep.); only few short resting periods occur during the night and most of the rest occurs during the day. Underground dens are not regularly used as resting sites by foxes. The general opinion is that many individuals prefer to lie above ground outside the breeding season (Harris and Lloyd 1991) and that dens are used as resting sites only temporarily (Labhardt 1990) or even exceptionally (Artois 1989). But except for a study which showed that the use of dens by foxes changes according to the seasons (Weber 1985), only some scarce data concerning the resting sites of the Red fox could be found in the literature (i.e. Allan 1968, Dekker 1983, Artois et al. 1990, or Woollard and Harris 1990).

We present here data obtained from seven female foxes radio-tracked between 1989 and 1992.

\section{Study area}

The study area (altitude $1000-1290 \mathrm{~m}$ ) is situated in the Swiss Jura mountains. The landscape is typically rural with many open or semi-open areas (pastures and meadows/wooded pastures), some spruce-dominated forests and several isolated farms. The area contains few arable fields. Most of the soil cover is thin and therefore the number of dens is low (Meia and Weber 1992). 


\section{Methods}

Seven adult female Red foxes Vulpes vulpes (Linnaeus, 1758) were fitted with radio-collars (Wildlife Materials Inc., Carbondale, USA). They were caught between September 1989 and February 1992 (Table 1) using stopped neck snares. The transmitters were fitted with an indicator of activity. The foxes were monitored using two methods: (1) daily diurnal locations ( $1 \mathrm{fix} /$ animal/ day during the "diurnal resting period"), and (2) 24-hour tracking sessions ( $1 \mathrm{fix} /$ animal/ 15 minutes for 24 hours, every week during the month following capture, then every two weeks). The weather conditions (fine, cloudy, foggy, wet or snowy) were also recorded and presence or absence of snow cover noted. None of the radio-tagged vixens bred during the monitoring period.

Resting sites were ranked in six categories:

1. "den" - underground or above ground at the den site ( $\leq 25 \mathrm{~m}$ from den site),

2. "surface": 2.1. "forest", above ground in a forest, 2.2. "forest edge", above ground in a forest edge (within $25 \mathrm{~m}$ of the boundary between forest and open area), 2.3. "wooded pasture", above ground in a wooded pasture, 2.4. "pasture", above ground in a pasture, meadow or cultivated field, 2.5. "building", in a human construction.

The home ranges presented in this paper were calculated using the minimum convex polygon method ( $100 \%$ of the fixes).

Table 1. Age of foxes (years), duration of radio-tracking and number of 24-hour tracking sessions (24HTS).

\begin{tabular}{lccc}
\hline Vixen & Age & Tracking period & 24HTS \\
\hline F2 & 1 & $20.09 .89-27.03 .90$ & 15 \\
F3 & $4(5)$ & $08.11 .89-03.12 .89$ & 3 \\
F8 & 1 & $23.01 .92-29.02 .92$ & 5 \\
F10 & 1 & $11.08 .90-23.01 .91$ & 13 \\
F11 & 1 & $03.02 .91-02.09 .91$ & 17 \\
F12 & $4(5)$ & $09.02 .91-21.12 .91$ & 24 \\
F19 & 3 & $13.07 .01-29.02 .92$ & 19 \\
\hline
\end{tabular}

\section{Results}

\section{Characteristics of resting sites}

Nocturnal resting sites

During the night, foxes seldom rested at a den site (four cases out of 412 observed resting periods) and never in buildings. Usually they did not move from a present habitat to rest: they lay where they had been active. Four of the seven radio-tracked vixens $(\mathrm{F} 3, \mathrm{~F} 8, \mathrm{~F} 10, \mathrm{~F} 11)$ used the different habitats available to them in the same proportion either to rest or be active (Table $2, \chi^{2}, p>0.05$ ). The three others (F2, F12 and F19) showed differences in active/resting habitat preferences (Table $2, \chi^{2}, p<0.05$ ); this probably corresponded to a preference to rest near an edge rather than in totally open land. 
Table 2. Comparison of the number of resting periods in the different habitats (rest) and the number of active radio fixes in the different habitats (activity) during the night, for each vixen, ${ }^{*}$ - without "forest edge".

\begin{tabular}{llrrrrr}
\hline & & \multicolumn{3}{c}{ Number of locations (radio fixes) } & \multirow{2}{*}{$\chi^{2}$} \\
\cline { 3 - 5 } Vixen & Behaviour & Forest & $\begin{array}{c}\text { Forest } \\
\text { edge }\end{array}$ & $\begin{array}{c}\text { Wooded } \\
\text { pasture }\end{array}$ & Pasture & \\
\hline F2 & Rest & 8 & 19 & 16 & 24 & \\
& Activity & 59 & 85 & 89 & 354 & $p<0.05$ \\
F3 & Rest & 7 & 1 & 3 & 4 & \\
& Activity & 39 & 3 & 12 & 56 & ns* \\
F8 & Rest & 4 & 6 & 11 & 3 & \\
& Activity & 32 & 47 & 62 & 52 & ns \\
F10 & Rest & 15 & 11 & 12 & 15 & \\
& Activity & 139 & 72 & 88 & 155 & ns \\
F11 & Rest & 11 & 12 & 14 & 33 & \\
& Activity & 65 & 62 & 112 & 247 & ns \\
F12 & Rest & 30 & 44 & 4 & 39 & \\
& Activity & 160 & 134 & 11 & 336 & $p<0.05$ \\
F19 & Rest & 3 & 9 & 37 & 10 & \\
& Activity & 32 & 36 & 323 & 245 & $p<0.05$ \\
\hline
\end{tabular}

Diurnal resting sites

The diurnal resting sites were always hidden; resting in the "pasture" habitat corresponded only to areas with high grass or cereals and therefore it occurred from late spring to late summer. In the same way, foxes did not rest during the day in front of a forest edge but always in the cover; for this reason, we included the "forest edge" data in the "forest" category.

There were variations between individuals and seasons (Table 3, Fig. 1). The seasonal pattern of use of dens was examined by comparing the values of the "den" category with the total of the other categories. No difference between seasons was found for F2 and F3 (Fisher test, $p>0.05$ ); these foxes rested always underground during the period they were monitored. Another vixen (F19) showed the opposite pattern: it seldom rested underground in autumn and winter (no difference between these seasons, Fisher test, $p<0.05$ ) but we located it several days in a den in summer (Fisher test, $p<0.05$ ). This result is related to the fact that it had reared cubs just before we caught it in mid-July. The other vixens (F10, F11, F12) used dens more frequently in autumn/winter than in summer (Fisher test, $p<$ 0.05 ) but the rest occurred always partly above ground; the change is gradual by F12 - no difference between autumn and winter and between winter and spring (Fisher test, $p>0.05$ ). The comparisons between individuals, for each season, 
Table 3. Number of locations in underground (den) or "surface" resting sites during the day. Comparisons between seasons for each vixen.

\begin{tabular}{llrrl}
\hline \multirow{2}{*}{ Vixen } & Season & \multicolumn{2}{c}{ Number of locations } & \\
\cline { 3 - 3 } & & Den & "Surfacen & Fisher test \\
(comparisons between seasons)
\end{tabular}

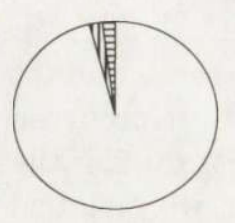

F2 WINTER

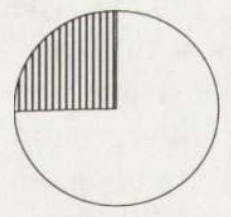

F10 WINTER

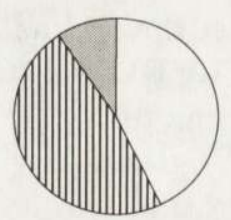

F12 WINTER

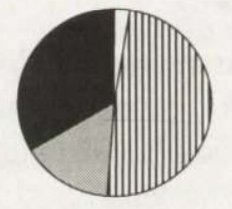

F11 SUMMER

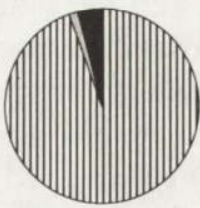

F19 SUMMER

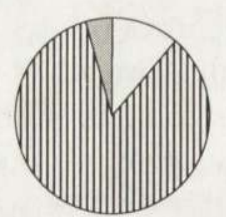

F12 SUMMER

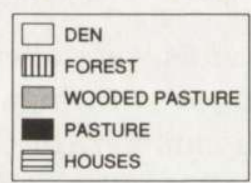

Fig. 1. Percentages of locations in the different habitats for the diurnal rest. Some examples. 
confirmed the above mentioned results. No difference was found between F2 and F3 which rested always in a den (Fisher test, $p>0.05$ ). In summer all radio-tracked foxes rested only exceptionally underground (Fisher test, $p>0.05$ ), except for F19, but during the other seasons each fox had its own strategy: only the comparison between F8 and F10 in winter showed no significant difference (Fisher test, $p>0.05$ ).

The location of "surface" resting sites varied with the individuals and the seasons. Only one of the monitored vixens (F11/ summer) was regularly located in the pasture habitat. The wooded pastures were always less used than the forests and only one fox (F2) rested once in a building. The foxes which used dens occasionally (F8, F10, F11, and F12) rested above ground also during cloudy, foggy, wet or snowy weather (Table 4). Only F12 rested less frequently above ground when the weather was bad and used a den (Table 4, Fisher test, $p<0.05$ ). During winter, snow cover seemed to induce two of the same individuals (F10, F12) to rest underground (Table 4 , Fisher test, $p<0.05$ ). During the hunting season (September to February, 3 days/week), the use of a den by these foxes did not correspond to the hunting days (Table 4).

As we considered the percentage of open areas in the home range of the foxes, we could separate two groups. The vixens which used dens continually or almost continually (F2, F3, F8) had more open areas in their home range than the other vixens (Table 5 , Mann-Whitney $U$-test, $p<0.05$ ). A positive rank correlation could be found between the percent of locations of the fox in a den and the percent of open areas in the home range (Table 5). There was no correlation between the number of dens in the home range and the use of dens as resting sites (Table 5).

\section{Use of diurnal resting sites}

Movements between resting sites during the day

Using the results of the 24-hour tracking sessions (Table 1) we looked at the number of changes of resting sites (den or surface) during the day. Foxes could move to another resting site up to 4 times within a half day, but generally they did not change or moved once (no change -122 cases, 1 change $-48,2$ changes $-11,3$ changes $-9,4$ changes -1 ). The distances between two successively used resting sites varied from 50 to $2500 \mathrm{~m}$ (in metres: $\bar{x}=330, \mathrm{SD}=400$ ) and the time used in moving was generally short (in minutes: $\bar{x}=23, \mathrm{SD}=14$, range $15-75$ ). When the foxes rested in a den, they left it for another site less frequently than when resting at a "surface" site (Fisher test, $p<0.05$ ). Foxes moved generally to a "surface" resting site. Twelve of the 101 displacements were caused by disturbance, usually human.

\section{Number and distribution of diurnal resting sites}

In order to compare the number of resting sites used by all foxes, we have calculated an "index of utilization" ( $n /$ r.s.) which corresponds to the number of daily fixes $(n)$ divided by the number of resting sites (r.s.) found during the seasons. 
Table 4. Number of locations in underground (den) or "surface" resting sites according to weather, snow cover and hunting days.

\begin{tabular}{|c|c|c|c|c|c|c|c|c|c|}
\hline \multirow{2}{*}{ Factor } & & \multicolumn{8}{|c|}{ Number of locations } \\
\hline & & \multicolumn{2}{|c|}{$\begin{array}{c}\text { F8 } \\
\text { Den "Surface" }\end{array}$} & \multicolumn{2}{|c|}{$\begin{array}{c}\text { F10 } \\
\text { Den "Surface" }\end{array}$} & \multicolumn{2}{|c|}{$\begin{array}{c}\text { F11 } \\
\text { Den "Surface" }\end{array}$} & \multicolumn{2}{|c|}{$\begin{array}{c}\text { F12 } \\
\text { Den "Surface" }\end{array}$} \\
\hline \multirow[t]{3}{*}{ Weather } & fine & 14 & 6 & 40 & 29 & 7 & 74 & 6 & 115 \\
\hline & $\begin{array}{l}\text { cloudy, fog, wet, } \\
\text { snowy }\end{array}$ & 15 & 2 & 56 & 27 & 6 & 87 & 23 & 118 \\
\hline & Fisher test & \multicolumn{2}{|c|}{ ns } & \multicolumn{2}{|c|}{ ns } & \multicolumn{2}{|c|}{ ns } & \multicolumn{2}{|c|}{$p<0.05$} \\
\hline \multirow[t]{3}{*}{ Snow cover } & presence & 8 & 4 & 34 & 7 & 7 & 11 & 4 & 7 \\
\hline & absence & 23 & 2 & 4 & 6 & 1 & 2 & 0 & 18 \\
\hline & Fisher test & \multicolumn{2}{|c|}{ ns } & \multicolumn{2}{|c|}{$p<0.05$} & \multicolumn{2}{|c|}{ ns } & \multicolumn{2}{|c|}{$p<0.05$} \\
\hline \multirow[t]{3}{*}{ Hunting day } & yes & 9 & 1 & 43 & 16 & 3 & 1 & 10 & 32 \\
\hline & & 11 & 2 & 62 & 23 & 1 & 3 & 11 & 44 \\
\hline & Fisher test & \multicolumn{2}{|c|}{ ns } & \multicolumn{2}{|c|}{ ns } & \multicolumn{2}{|c|}{ ns } & \multicolumn{2}{|c|}{ ns } \\
\hline
\end{tabular}

Table 5. Relation between the underground rest and the surface of open areas or the number of dens in the home range, $R \mathrm{~s}$ - Spearman rank correlation coeficient.

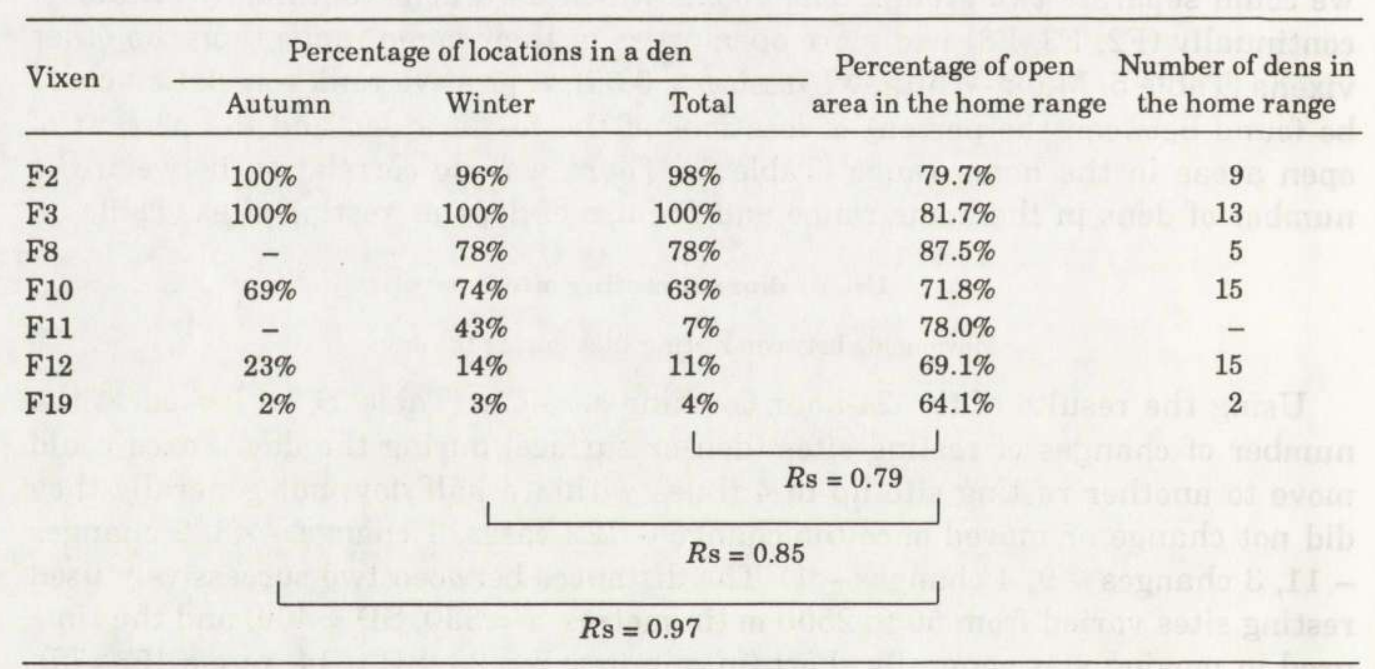

The results showed (Table 6) that the foxes which rested more often in a den than above ground (F2, F3, F8, F10 autumn and winter) used a lower number of resting sites than others (Mann Whitney $U$-test, $p<0.05$ ). The number of succesive locations in the same resting site varied from 1 to 28 (Table 6). It was also higher for the foxes which rested more often in a den than above ground (Mann-Whitney $U$-test, $p<0.05)$. Fig. 2 illustrates these two patterns.

The home ranges of the monitored vixens covered between 127 and 292 ha except for F11 which travelled across an area of about 3400 ha but used regularly 
Table 6. Index of utilization of the resting sites (n/r.s.) and average duration of utilization (expressed in successive radio fixes in the same site). Results are presented in bold when underground rest is the most numerous.

\begin{tabular}{|c|c|c|c|c|c|c|c|c|}
\hline \multirow{2}{*}{ Vixen } & \multirow{2}{*}{ Season } & \multirow{2}{*}{$\begin{array}{l}\text { Number of } \\
\text { fixes } \\
(n)\end{array}$} & \multirow{2}{*}{$\begin{array}{l}\text { Number of } \\
\text { resting sites } \\
\text { (r.s.) }\end{array}$} & \multirow{2}{*}{$n /$ r.s. } & \multicolumn{4}{|c|}{ Successive radio fixes in the same site } \\
\hline & & & & & $\bar{x}$ & SD & $\min$ & $\max$ \\
\hline \multirow[t]{3}{*}{ F2 } & autumn & 61 & 3 & 20 & 5.5 & 8.3 & 1 & 28 \\
\hline & winter & 49 & 5 & 10 & 7 & 10.4 & 1 & 5 \\
\hline & spring & 17 & 1 & 17 & 17 & - & 17 & 17 \\
\hline F3 & autumn & 24 & 3 & 8 & 8 & 11.3 & 1 & 21 \\
\hline F8 & winter & 37 & 5 & 7 & 3.1 & 6 & 1 & 22 \\
\hline \multirow[t]{3}{*}{ F10 } & summer & 18 & 13 & 1 & 1.1 & 0.3 & 1 & 2 \\
\hline & autumn & 83 & 11 & 8 & 1.6 & 1.4 & 1 & 7 \\
\hline & winter & 51 & 8 & 6 & 3 & 3.5 & 1 & 14 \\
\hline \multirow[t]{3}{*}{ F11 } & winter & 21 & 7 & 3 & 1.2 & 0.4 & 1 & 2 \\
\hline & spring & 75 & 37 & 2 & 1.1 & 0.3 & 1 & 2 \\
\hline & summer & 78 & 34 & 2 & 1.3 & 0.8 & 1 & 6 \\
\hline \multirow[t]{5}{*}{ F12 } & winter & 13 & 7 & 2 & 1.4 & 0.7 & 1 & 3 \\
\hline & spring & 79 & 21 & 4 & 1.3 & 0.6 & 1 & 3 \\
\hline & summer & 73 & 17 & 4 & 1.3 & 0.9 & 1 & 6 \\
\hline & autumn & 81 & 16 & 5 & 1.3 & 1.4 & 1 & 11 \\
\hline & winter & 16 & 3 & 5 & 6.4 & 5.6 & 2 & 6 \\
\hline \multirow[t]{3}{*}{ F19 } & summer & 45 & 6 & 7 & 1.4 & 0.7 & 1 & 4 \\
\hline & autumn & 82 & 6 & 14 & 1.7 & 1.1 & 1 & 4 \\
\hline & winter & 63 & 6 & 10 & 2.2 & 1.9 & 1 & 9 \\
\hline
\end{tabular}

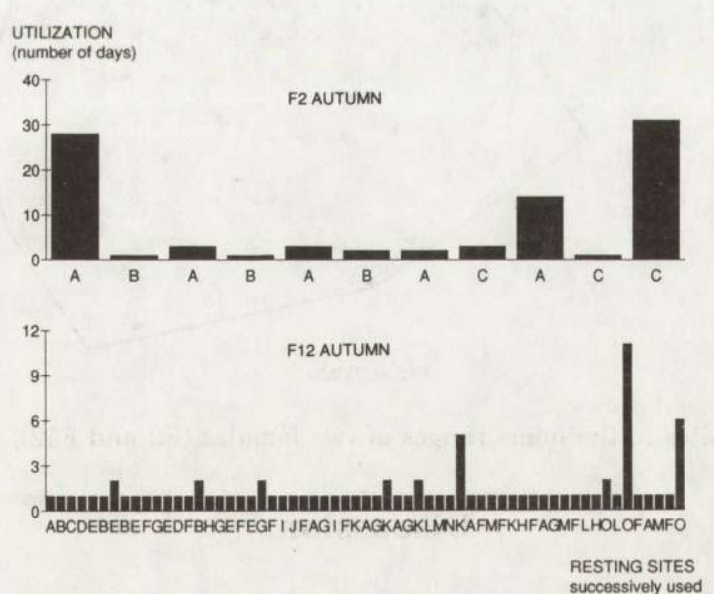

Fig. 2. Difference in use of resting sites by two females: F2 studied in autumn ( 89 consecutive days of undergound rest) and F12 studied in autumn ( 86 consecutive days of rest above ground). Each resting site is represented by one capital letter. 
only certain parts of this area. The resting sites were not distributed evenly in the home ranges and they could be very close to the borders (Fig. 3). They were not situated in the most travelled areas: no relation was found between the number of resting sites and the number of active radio fixes (24-hour tracking sessions) in equal size squares dividing the home ranges (Spearman rank correlation). The foxes used only a small proportion of the dens located in their home ranges. The number of used dens varied from one to three: 1 den in F11 and F19, 2 dens in F8 and F10, 3 dens in F2, F3, and F12 (Fig. 3).

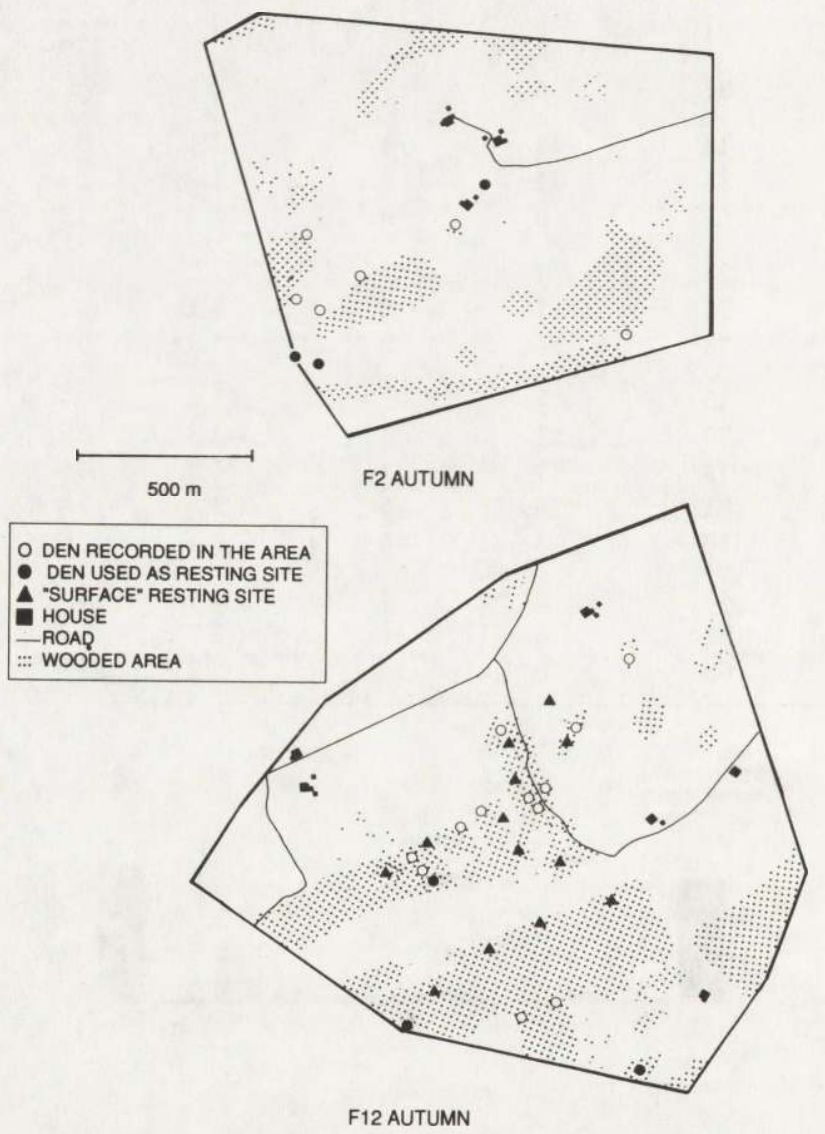

Fig. 3. Location resting sites in the home ranges of two females (F2 and F12), studied in autumn.

\section{Discussion}

Type of resting sites

Foxes show a great variablity in their resting strategy; there are great intraand interindividual differences. Dekker (1983) shows that in the same area, foxes 
could lie above or underground. Poulle (1991) also observed that foxes use a large spectrum of sites to rest: in her study area, forest was the most commonly used habitat except in summer when foxes were mainly lying in cereals, and dens were rarely used. The type of available habitats seems then to have a great influence (cereals are not abundant in our study area). A constant feature is that foxes need a quiet place to spend the diurnal period; for this reason, they do not rest near buildings in our area. On that point, the conditions in the Swiss Jura mountains do not correspond to the "quiet gardens" used by urban foxes, for example in Britain (Harris 1977); hunting was very prevalent in the past and is still sustained in certains parts of the area.

The use of dens is noticeably more frequent in winter than in summer, but the annual variations observed by Weber (1985) are not applicable in all cases. In our area, some individuals rest all through the year in dens. Several months after the monitoring period, the vixens which had been regularly located in dens continued to rest underground and they were regularly observed going in or out of their habitual dens. This is probably due to the number of shelters in the area. The fox which never rested underground (F19) had at its disposal a very quiet, steep and undisturbed forest; this was not the case of vixens which continually used dens (F2, F3, F8) which all came from the same part of the study area where there is little cover and where hunters are particularly active. Lloyd (1980) also mentions that foxes lay below more often when cover is scarce or not secure.

The choice of the resting site was rarely influenced by weather, except in extreme conditions. Weber (1985), and Harris and Lloyd (1991) state that foxes prefer to lie in dens during bad weather. This pattern was not the rule in our area: during rain, foxes generally continue to rest above ground. We think that the current opinion that foxes avoid rain because it decreases the insulating power of the fur (Artois 1989) should be revised. We often observed foxes during the night which rested in totally open areas during heavy rain.

\section{Number and location of resting sites in the home ranges}

Although Capt and Stalder (1991) observed that foxes lie in the same place during the day, without moving, Artois et al. (1990), and Woollard and Harris (1990) show the use of several resting sites. We observed that there are few sites when dens are used probably due to the limited number of dens in the area. The larger number of sites used by foxes which rest above ground could be explained by three reasons. First, a fox lying above ground could be disturbed more easily (walkers). Second, in the areas with enough cover to rest above ground, foxes find many suitable sites to rest and could move from one site to another to patrol their home range. This survey function is supported by the great number of observed movements during the day without a visible disturbing factor and by the cases of foxes leaving a den to rest in another one or above ground. Finally, a "comfort" reason could explain some of the movements (change of the direction of the sun or arrival of another individual on the site). The fact that some dens (Ables 1969, 
Eiberle 1975, Fabrigoule and Maurel 1982) or some "surface" areas (Artois et al. 1990) are prefered was confirmed in this study. Security and maybe comfort could explain this fact, but a social reason is more likely. We observed, as Harris 1980) did, that several individuals used the same resting sites and Poulle 1991) emphasized that the social interactions between foxes happen essentially during the resting period.

Like Artois (1985) who noticed that foxes could move a long way to reach their foraging areas, we observed that the daytime iesting places and the nociurnal hunting areas do not overlap. This contradicts one part of the model of Neber (1985) which predicts that foxes try to reduce the travel costs between these two zones; we think that the small size of the home ranges could make these costs negligible. The often peripheral location of resting sites, mainly dens, emphazised the great part they probably play in the establishment of the home ranges

Acknowledgements: We wish to thank particularly S. Aubry for his precious technical assistance as well as Dr R. Hewson for reviewing our manuscript. We also thank Prof C. Mermod for his support and N. Ferrari for field assitance. This study was supported by Grant 31-27766.89/2 of the Swiss National Science Found.

\section{References}

Ables E. D. 1969. Activity studies of red foxes in southern Wisconsin. J. Wildl. Manag. 33: 45-153.

Allan R. A. 1968. Movements and daily activities of fox as determined by visual observations and radio tracking. Proc. Iowa Acad. Sci. 75: $147-151$.

Artois M. 1985. Utilisation de l'espace et du temps chez le renard (Vulpes vulpes) et le chat forestier (Felis silvestris) en Lorraine. Gibier Faune Sauvage 3: 33 - 57.

Artois M. 1989. Le renard roux (Vulpes vulpes Linnaeus, 1758). [In: Encyclopédie des carnirores de France 3. Société française pour l'étude et la protection des mammiferes, eds]. Nort 3/Erdre, France: $1-90$.

Artois M., Aubert M. and Stahl P. 1990. Organisation spatiale du renard roux (Vulpes vulpes L., 1758) en zone d'enzootie de rage en Lorraine. Rev. Ecol. (Terre Vie) 45: 113 - 134 .

Capt S. and Stalder H. 1991. Aspekte der Raumnutzung von Füchsen im alpinen Ravm. [In: Fuchs-Symposium, Koblenz, 2-3. März 1990. C. Commichau and H. Sprankel, eds]. Arbeitskreise Wilbiologie an der Justus-Liebig-Universität Giessen e.V., Giessen e.V.: 33 - 38.

Dekker D. 1983. Denning and foraging habits of red foxes, Vulpes vulpes, and their interaction with coyotes, Canis latrans, in Central Alberta, 1972 - 1981. Can. Fld. Nat. 97: $303-306$.

Eiberle K. 1975. Zur Anlage und Benützung der Fuchsbaue im jagdlichen Versuchsrevier der ETH Zürich. Schweizer. Z. Forstwesen 126: $41-64$.

Fabrigoule C. and Maurel D. 1982. Radio-tracking study of foxes' movements related to their home range. A cognitive map hypothesis. Quart. J. Exp. Psychol. 34B: 195-208.

Harris S. 1977. Distribution, habitat utilization and age structure of a suburban fox (Vulpes vulpes) population. Mammal Rev. 7: 25 - 39 .

Harris S. 1980. Home ranges and pattern of distribution of foxes (Vulpes vulpes) in an urban area, as revealed by radio tracking. [In: A handbook of biotelemetry and radio tracking. C. J. Amlaner and D. W. Macdonald, eds]. Pergamon Press, Oxford: $685-690$.

Harris S. and Lloyd H. G. 1991. Fox Vulpes vulpes. [In: The handbook of British mammals (3rd edn). G. B. Corbet and S. Harris, eds]. Blackwell Scientific Publications, Oxford: $351-367$.

Labhardt F. 1990. Der Rotfuchs. Verlag Paul Parey, Hamburg: 1 - 158. 
Lloyd H. G. 1980. Habitat requirements of the red fox. [In: Biogeographica 18, The red fox. E. Zimen, ed]. Dr W. Junk bv Publishers, The Hague: $7-25$.

Meia J. S. and Weber J. M. 1992. Characteristics and distribution of breeding dens of the red fox (Vulpes vulpes) in a mountainous habitat. Z. Säugetierk. 57: 137-143.

Poulle M. L. 1991. Eco-éthologie du renard roux (Vulpes vulpes) en Lorraine: influence du mode de distribution des ressources sur le partage de l'espace et les relations interindividuelles. Ph.D. Thesis, University Louis Pasteur, Strasbourg, France: $1-191$.

Weber D. 1985. Zur Baubenutzung und ihrer Funktion beim Fuchs (Vulpes vulpes L.). Z. Säugetierk. 50: $356-368$.

Woollard T. and Harris S. 1990. A behavioural comparison of dispersing and non- dispersing foxes (Vulpes vulpes) and an evaluation of some dispersal hypotheses. J. Anim. Ecol. 59: $709-722$.

Received 2 October 1992, accepted 23 February 1993. 